\title{
Theory of Laplace Analysis of Non-Gaussian Noise
}

\author{
B. M. Grafov ${ }^{\mathrm{a}, z}$ and I. B. Grafova ${ }^{\mathrm{b}}$ \\ ${ }^{a}$ Frumkin Institute of Electrochemistry, Russian Academy of Sciences, \\ Leninskii pr. 31, Moscow, 119071 Russia \\ ${ }^{b}$ Department of Economics, University of Michigan, \\ 611 Tappan st., Ann Arbor, Michigan 48109, USA
}

Received September 16, 2003

\begin{abstract}
An algorithm for directly calculating third-order noise operation spectra, which includes no evaluation of the third-order correlation function as a preliminary stage, is found. For the Ershler-Randles circuit, an expression is found, which links bispectra of the equilibrium electrode potential fluctuation determined in the imaginary and real axes of the Laplace plane. Advantages of using the Laplace space in studies of the fine nonGaussian structure of random time series are discussed.
\end{abstract}

Key words: non-Gaussian noise, bispectra, Laplace transform

\section{INTRODUCTION}

Nowadays information technologies make fast strides connected with the measurement and analysis of the intrinsic noise in systems of diverse nature, which are important not only for modern electronics but also for numerous fields of science and technology, including biophysics and fatigue tests of materials [1-10]. Considerable interest is devoted to a fine non-Gaussian structure of the intrinsic noise [11-17]. The noise information technologies are on the increase in electrochemistry as well [18-28].

In this work we will develop a theory for analyzing non-Gaussian noise in the Laplace space [29]. We will deal with measuring third-order operation spectra or, which is the same, measuring the operation bispectra [30-32]. We shall discuss random time series with both continuous and discrete time. The theory of secondorder operation spectra was dealt with in [24, 33-35].

\section{THE FOURIER AND LAPLACE BISPECTRA}

The Fourier bispectra $\left\langle y_{v-\omega} y_{\omega} y_{v}^{*}\right\rangle$ depend on frequencies $\omega$ and $v$. They are defined by equations (1) and (2) for continuous $(t)$ and discrete $\left(t=m t_{0}\right)$ time $\left(t_{0}\right.$ is the sampling interval) [36]:

$$
\begin{gathered}
\left\langle y_{v-\omega} y_{\omega} y_{v}^{*}\right\rangle \\
=4 \int_{-\infty}^{+\infty} d t_{1} \int_{-\infty}^{+\infty} d t_{2} \exp \left(-j \omega t_{1}+j v t_{2}\right)\left\langle y(0) y\left(t_{1}\right) y\left(t_{2}\right)\right\rangle,
\end{gathered}
$$

\footnotetext{
${ }^{z}$ Corresponding author, e-mail: vek@elchem.ac.ru
}

$$
=4 \sum_{m=-\infty} \sum_{n=-\infty}^{+\infty} t_{0}^{2} \exp \left(-j \omega t_{1}+j v t_{2}\right)\left\langle y(0) y\left(t_{1}\right) y\left(t_{2}\right)\right\rangle .
$$

Here, $j=\sqrt{-1}$ and $\left\langle y(0) y\left(t_{1}\right) y\left(t_{2}\right)\right\rangle$ denotes a third-order correlation function of a random steady-state process $y(t)$ that has a zero mean. By $y(t)$ we will understand either the electrical current or voltage fluctuations. In equation (2), $t_{1}=m t_{0}$ and $t_{2}=n t_{0}$.

The operation bispectra correspond to the substitution of the Laplace frequencies $p$ and $q$ for the Fourier frequencies $\omega$ and $v: j \omega \longrightarrow p$ and $(-j v) \longrightarrow q$. The integration (summation) range changes as well: a onesided operation replaces a two-sided one. From (1) and (2) we define the operation bispectra as follows:

$$
\left\langle y_{0} y_{p} y_{q}\right\rangle=16 K(p, q) \text {. }
$$

Here, $K(p, q)$ is the Laplace image of the third-order correlation function $\left\langle y(0) y\left(t_{1}\right) y\left(t_{2}\right)\right\rangle$. Equation

$$
\begin{gathered}
K(p, q) \\
=\int_{0}^{+\infty} d t_{1} \int_{0}^{+\infty} d t_{2} \exp \left(-p t_{1}-q t_{2}\right)\left\langle y(0) y\left(t_{1}\right) y\left(t_{2}\right)\right\rangle, \\
K(p, q)=\sum_{m=0}^{\infty} t_{0} \sum_{n=0}^{\infty} t_{0}\left\langle y(0) y\left(t_{1}\right) y\left(t_{2}\right)\right\rangle
\end{gathered}
$$


defines $K(p, q)$ for continuous time and equation

$$
\begin{gathered}
\times \exp \left(-p t_{1}-q t_{2}\right)-\frac{1}{2} t_{0} \sum_{m=0}^{\infty} t_{0}\left\langle y(0) y\left(t_{1}\right) y(0)\right\rangle \\
\times \exp \left(-p t_{1}\right)-\frac{1}{2} t_{0} \sum_{n=0}^{\infty} t_{0}\left\langle y(0) y(0) y\left(t_{2}\right)\right\rangle \exp \left(-q t_{2}\right) \\
+\frac{1}{3} t_{0}^{2}\langle y(0) y(0) y(0)\rangle .
\end{gathered}
$$

for discrete time. In (5), $t_{1}=m t_{0}$ and $t_{2}=n t_{0}$. Here and in what follows, operation frequencies $p$ and $q$ are real positive numbers. The quantity $K(p, q)$ is symmetrical with respect to frequencies $p$ and $q$

$$
K(p, q)=K(q, p)
$$

by definition. A third-order cumulant function $\left\langle y(0) y\left(t_{1}\right) y\left(t_{2}\right)\right\rangle$ can be found over the entire time plane $\left(t_{1}, t_{2}\right)$ when it is known in the first quadrant [36]. Therefore, a Laplace image of the cumulant function $K(p, q)$ with Laplace frequencies $p$ and $q$ uniquely defines the initial cumulant function $\left\langle y(0) y\left(t_{1}\right) y\left(t_{2}\right)\right\rangle$.

\section{RANDOM SERIES WITH CONTINUOUS TIME}

The Laplace transform $Y(p)$ of the initial random process $y(t)$

$$
Y(p)=\int_{0}^{+\infty} d t \exp (-p t) y(t)
$$

is a random quantity. We will use it for constructing a third-order cumulant

$$
\begin{gathered}
\langle Y(p) Y(q) Y(r)\rangle=\int_{0}^{+\infty} d t_{1} \int_{0}^{+\infty} d t_{2} \int_{0}^{+\infty} d t_{3} \\
\times\left[\exp \left(-p t_{1}-q t_{2}-r t_{3}\right)\left\langle y\left(t_{1}\right) y\left(t_{2}\right) y\left(t_{3}\right)\right\rangle\right] .
\end{gathered}
$$

Here, $p, q$, and $r$ are operation frequencies, and the angle brackets imply the averaging over an ensemble of realizations. We assume that the steady-state random processes under discussion are ergodic. Therefore, an averaging operation means the averaging either over an ensemble of identical stochastic systems or over an ensemble of long observation times concerning a single stochastic system.

The integral in the right-hand part of (8) can be written as the sum of three integrals

$$
\int_{0}^{+\infty} d t_{1} \int_{0}^{+\infty} d t_{2} \int_{0}^{+\infty} d t_{3}[\ldots]=J_{1}+J_{2}+J_{3},
$$

where

$$
J_{1}=\int_{0}^{+\infty} d t_{1} \int_{t_{1}}^{+\infty} d t_{2} \int_{t_{1}}^{+\infty} d t_{3}[\ldots]
$$

$$
\begin{gathered}
J_{2}=\int_{0}^{+\infty} d t_{2} \int_{t_{2}}^{+\infty} d t_{1} \int_{t_{2}}^{+\infty} d t_{3}[\ldots], \\
J_{3}=\int_{0}^{+\infty} d t_{3} \int_{t_{3}}^{+\infty} d t_{1} \int_{t_{3}}^{+\infty} d t_{2}[\ldots] .
\end{gathered}
$$

We will first calculate $J_{1}$ :

$$
\begin{gathered}
J_{1}=\int_{0}^{+\infty} d t_{1} \int_{t_{1}}^{+\infty} d t_{2} \int_{t_{1}}^{+\infty} d t_{3} \\
\times\left[\exp \left(-p t_{1}-q t_{2}-r t_{3}\right)\left\langle y(0) y\left(t_{2}-t_{1}\right) y\left(t_{3}-t_{1}\right)\right\rangle\right] .
\end{gathered}
$$

After replacing the integration variables, then $t_{4}=t_{2}-t_{1}$, $t_{5}=t_{3}-t_{1}$

$$
\begin{gathered}
J_{1}=\int_{0}^{+\infty} d t_{1} \exp \left(-p t_{1}-q t_{1}-r t_{1}\right) \\
\times \int_{0}^{+\infty} d t_{4} \int_{0}^{+\infty} d t_{5}\left[\exp \left(-q t_{4}-r t_{5}\right)\left\langle y(0) y\left(t_{4}\right) y\left(t_{5}\right)\right\rangle\right],
\end{gathered}
$$

therefore,

$$
J_{1}=\frac{K(q, r)}{p+q+r}
$$

similarly,

$$
J_{2}=\frac{K(p, r)}{p+q+r}, \quad J_{3}=\frac{K(p, q)}{p+q+r}
$$

and the third-order cumulant we sought for is

$$
\begin{gathered}
\langle Y(p) Y(q) Y(r)\rangle \\
=[K(p, q)+K(p, r)+K(q, r)] /(p+q+r) .
\end{gathered}
$$

We set all operation frequencies in (12) equal to each other: $q=r=p$. This gives the algorithm

$$
\left\langle y_{0} y_{p}^{2}\right\rangle=16 K(p, p)=16 p\left\langle Y^{3}(p)\right\rangle
$$

for calculating the operation bispectra at identical operation frequencies. Setting $r=q$ in (12), then

$$
\left\langle Y(p) Y^{2}(q)\right\rangle(p+2 q)=2 K(p, q)+K(q, q) .
$$

By combining (13) and (14) we come to general algorithm

$$
\left\langle y_{0} y_{p} y_{q}\right\rangle=8\left[(p+2 q)\left\langle Y(p) Y^{2}(q)\right\rangle-q\left\langle Y^{3}(q)\right\rangle\right]
$$

for calculating the operation bispectra that depend on two independent Laplace frequencies $p$ and $q$. As the integrals with exponential functions rapidly converge, the final realization interval for random process $y(t)$ can be considered as infinitely wide. 


\section{OPERATION BISPECTRA \\ FOR THE ERSHLER-RANDLES CIRCUIT}

The Ershler-Randles circuit is a common electrochemical ac circuit $[37,38]$, which consists of faradaic resistance $R$ and double-layer capacitance $C$ connected in parallel. The complex conductance $G_{\omega}$ and operation admittance $G_{p}$ of the Ershler-Randles circuit are defined as follows:

$$
G_{\omega}=R^{-1}+j \omega C, \quad G_{p}=R^{-1}+p C .
$$

The potential response function $H^{E}(t)$ exponentially depends on the time

$$
H^{E}(t)=C^{-1} \exp \left(-t R^{-1} C^{-1}\right) .
$$

A faradaic processes is highly nonlinear and is characterized by white noise. Therefore, the Langevin linear stochastic equation [17] for fluctuations of the equilibrium electrode potential $e(t)$

$$
e(t)=\int_{-\infty}^{+\infty} d t_{1} H^{E}\left(t-t_{1}\right) i\left(t_{1}\right)
$$

contains the current $i(t)$ possessing characteristics of nonlinear white noise. As a result, the third-order correlation function $\left\langle e(0) e\left(t_{1}\right) e\left(t_{2}\right)\right\rangle$ that corresponds to $e(t)$ is proportional to the integral of the product of three response functions $[30,39]$

$$
\left\langle e(0) e\left(t_{1}\right) e\left(t_{2}\right)\right\rangle \sim \int_{-\infty}^{+\infty} d t_{1} H^{E}(t) H^{E}\left(t+t_{1}\right) H^{E}\left(t+t_{2}\right) .
$$

Based on (19), for a Fourier bispectrum with equal frequencies and a Laplace bispectrum with equal operation frequencies, we obtain expressions

$$
\begin{gathered}
\left\langle e_{0} e_{\omega}^{2}\right\rangle \sim-\frac{1}{\left[1+(\omega R C)^{2}\right]}, \\
\left\langle e_{0} e_{p}^{2}\right\rangle \sim \frac{1}{\left(1+p R C^{2}\right)},
\end{gathered}
$$

which are correct to a proportionality coefficient. Worth noting is different functional dependence of relevant bispectra on the Fourier frequency $\omega$ and the Laplace frequency $p$. Interestingly, equation (21) is the first example of modeling the third-order operation spectra. Calculations based on (19) suggest that, in the case of the Ershler-Randles circuit, the bispectra determined in the imaginary axis of the Laplace plane (Fourier bispectra) and the bispectra determined in the real axis of the Laplace plane (operation bispectra) are interrelated through the simple formula

$$
\frac{\left\langle e_{0} e_{\omega}^{2}\right\rangle}{\left\langle e_{0} e_{p}^{2}\right\rangle}=\frac{3(1+p R C)^{2}}{4\left[1+(\omega R C)^{2}\right]} .
$$

Using operation admittance $G_{p}$ and common admittance $G_{\omega}$ the latter may be rewritten as

$$
4\left\langle e_{0} e_{\omega}^{2}\right\rangle\left|G_{\omega}\right|^{2}=3\left\langle e_{0} e_{p}^{2}\right\rangle\left|G_{p}\right|^{2}
$$

We see that both the left- and right-hand parts of (23) equal some constant, which characterizes the noise properties of the Ershler-Randles circuit.

\section{RANDOM SERIES WITH DISCRETE TIME}

A similar analysis can be carried out for a random process with discrete time. However, here the Laplace image $Y(p)$ of the initial random process $y(t)$ is the result of applying the Laplace discrete transform:

$$
Y(p)=\sum_{m=0}^{\infty} t_{0} \exp (-p t) y(t),
$$

where $t=m t_{0}$. The modified form of (12) is

$$
\begin{gathered}
\langle Y(p) Y(q) Y(r)\rangle \\
=\frac{t_{0}}{1-\exp \left(-\sigma t_{0}\right)}[K(p, q)+K(p, r)+K(q, r)],
\end{gathered}
$$

where $\sigma=p+q+r$. The equation

$$
\left\langle y_{0} y_{p}^{2}\right\rangle=16 K(p, p)=16 \frac{1-\exp \left(-\sigma t_{0}\right)}{3 t_{0}}\left\langle Y^{3}(p)\right\rangle \text {. }
$$

is a discrete analog of (13). Finally, the equation

$$
\begin{aligned}
\left\langle y_{o} y_{p} y_{q}\right\rangle= & 8\left[\frac{1-\exp \left(-p t_{0}-2 q t_{0}\right)}{t_{0}}\left\langle Y(p) Y^{2}(q)\right\rangle\right. \\
& \left.-\frac{1-\exp \left(-3 q t_{0}\right)}{3 t_{0}}\left\langle Y^{3}(q)\right\rangle\right]
\end{aligned}
$$

is a discrete analog of (15). The detailed procedure of deriving (25) for operation bispectra corresponding to a random process with discrete time is given in Appendix.

\section{CONCLUSIONS}

The advantages of using the Laplace space for studying a fine non-Gaussian structure of random time series are:

(i) a clear statistical meaning of the third-order operation spectra (bispectra) and the possibility of their modeling, in particular, in the case of operation bispectra with equal Laplace frequencies;

(ii) an exponentially small systematic error in evaluating the operation bispectra. As a result, the traditional problem of spectra windows affecting the results of spectral analysis of a random time series loses its edge;

(iii) a high performance in the computer processing, caused by the possibility of using one-dimensional mass data when calculating operation bispectra with equal Laplace frequencies; and

(iv) a new source of useful information on the fine non-Gaussian structure of a fluctuation state of the system under study. 


\section{ACKNOWLEDGMENTS}

We are grateful to Profs. A.M. Kuznetsov, S.F. Timashev, M.V. Sviridov, K. Laszlo (Texas A\&M University), and Ch. Doering (University of Michigan) for extremely useful discussion of the problem of measuring and analyzing non-Gaussian noise.

This work was supported by the Russian Foundation for Basic Research, project no. 02-03-32114.

APPENDIX

The starting point in the calculation of operation bispectra is the equation

$$
Y(p)=\sum_{m=0}^{\infty} t_{0} \exp (-p t) y(t) .
$$

Using the discrete Laplace transform, it coverts a random time series $y(t)\left(t=m t_{0}\right.$, where $m$ is an integer $)$ to a random quantity $Y(p)$. Using (A.1), we will form a third-order cumulant $\langle Y(p) Y(q) Y(r)\rangle$, where the angle brackets denote the averaging over an ensemble of realizations of random process $y(t)$, while $p, q$, and $r$ are positive Laplace frequencies. For $\langle Y(p) Y(q) Y(r)\rangle$ we obtain the triple series

$$
\begin{gathered}
\langle Y(p) Y(q) Y(r)\rangle=\sum_{m=0}^{\infty} t_{0} \sum_{n=0}^{\infty} t_{0} \sum_{k=0}^{\infty} t_{0} \\
\times \exp \left(-p t-q t_{2}-r t_{3}\right)\left\langle y(t) y\left(t_{2}\right) y\left(t_{3}\right)\right\rangle .
\end{gathered}
$$

Here, $t_{2}=n t_{0}$ and $t_{3}=k t_{0}$ ( $n$ and $k$ are integers). The summation in the right-hand part of (A.2) is done over points of a discrete three-dimensional space $(m, n, k)$ via diagonal lines that form the same angle with all three coordinate axes. For example, the summation over points in a diagonal line passing through the point $(0, n, k)$ on the plane $m=0$ gives $a\left\langle y(0) y\left(t_{2}\right) y\left(t_{3}\right)\right\rangle \exp \left(-q t_{2}-r t_{3}\right)$, where $a=t_{0} /\left[1-\exp \left(-\sigma t_{0}\right)\right]$ and $\sigma=p+q+r$. The sum over all diagonal lines passing through the coordinate plane $m=0$ is

$$
\begin{gathered}
\sum(m=0) \\
=a \sum_{n=0}^{\infty} t_{0} \sum_{k=0}^{\infty} t_{0} \exp \left(-q t_{2}-r t_{3}\right)\left\langle y(0) y\left(t_{2}\right) y\left(t_{3}\right)\right\rangle,
\end{gathered}
$$

and similar summation over all diagonal lines passing through coordinate plane $n=0$ gives

$$
\begin{gathered}
\sum(n=0) \\
=a \sum_{m=0}^{\infty} t_{0} \sum_{k=0}^{\infty} t_{0} \exp \left(-p t-r t_{3}\right)\left(y(0) y(t) y\left(t_{3}\right)\right),
\end{gathered}
$$

while for the coordinate plane $k=0$ we obtain

$$
\begin{gathered}
\sum(k=0) \\
=a \sum_{m=0}^{\infty} t_{0} \sum_{n=0}^{\infty} t_{0} \exp \left(-p t-q t_{2}\right)\left\langle y(0) y(t) y\left(t_{2}\right)\right\rangle .
\end{gathered}
$$

Note that the diagonal line passing the origin was accounted for thrice; the diagonal lines passing through the points in the coordinate axes (other than the origin) were accounted for twice. Upon introducing a relevant correction, we obtain

$$
\begin{gathered}
\langle Y(p) Y(q) Y(r)\rangle=\sum(m=0)+\sum(n=0) \\
+\sum(k=0)-2 a t_{0}^{2}\left\langle y^{3}(0)\right\rangle-a t_{0} \sum_{m=1}^{\infty} t_{0}\{\exp (-p t) \\
+\exp (-q t)+\exp (-r t)\}\left\langle y^{2}(0) y(t)\right\rangle
\end{gathered}
$$

for the correlator. In the last (third) summand we introduce the summation, which starts with $m=0$. Then (A.6) becomes

$$
\begin{gathered}
\langle Y(p) Y(q) Y(r)\rangle=\sum(m=0)+\sum(n=0) \\
+\sum(k=0)-a t_{0} \sum_{m=0}^{\infty} t_{0}\{\exp (-p t) \\
+\exp (-q t)+\exp (-r t)\}\left\langle y^{2}(0) y(t)\right\rangle+a t_{0}^{2}\left\langle y^{3}(0)\right\rangle .
\end{gathered}
$$

Using (5), on the basis of (A.3)-(A.5) and (A.7), we obtain the sought-for expression

$$
\begin{gathered}
\langle Y(p) Y(q) Y(r)\rangle \\
=[K(p, q)+K(p, r)+K(q, r)] t_{0} /\left[1-\exp \left(-\sigma t_{0}\right)\right] .
\end{gathered}
$$

As seen, it coincides with (25).

\section{REFERENCES}

1. Proc. of SPIE Conf. Noise as a Tool for Studying Materials, Weissman, M.B., Israeloff, N.E., and Kogan, Sh., Eds., Santa Fe: SPIE, 2003, vol. 5112.

2. Van Kampen, N.G., Fluct. Noise Lett., 2001, vol. 1, p.1.

3. Bezrukov, S.M., Proc. 2nd Int. AIP Conf. Unsolved Problems of Noise and Fluctuations, Adelaide, June 1215, 1999, Abbott, D. and Kish, L., Eds., New York: AIP, 2000, p. 3.

4. Kogan, Sh., Electronic Noise and Fluctuations in Solids, Cambridge: Cambridge University Press, 1996.

5. Weissman, M.B., Rev. Mod. Phys., 1988, vol. 60, p. 537.

6. Gonzalez, N., Proc. 17th Conf. on Noise and Fluctuations, Prague, August 18-22, 2003, Sikula, J., Ed., Brno: CNRL, 2003, p. 607.

7. Iannaccone, G., Proc. 17th Conf. on Noise and Fluctuations, Prague, August 18-22, 2003, Sikula, J., Ed., Brno: CNRL, 2003, p. 614.

8. Sukhorukov, E.V., Pilgram, S., Jordan, A.N., and Buttiker, M., Proc. 17th Conf. on Noise and Fluctuations, Prague, August 18-22, 2003, Sikula, J., Ed., Brno: CNRL, 2003, p. 45. 
9. Baranov, V.M., Kapralov, E.Yu., and Kapralov, Yu.A., Zavod. Lab., Diagnost. Mater., 2003, vol. 69, p. 36.

10. Muravin, G., Inspection, Diagnostics, and Monitoring of Construction Materials and Structures by the Acoustic Emission Method, London: Minerva, 2000.

11. Yakimov, A.V., Belyakov, A.V., Perov, M.Yu., and Vandamme, L.K.J., Proc. of SPIE Conf. Noise and Information in Nanoelectronics: Sensors and Standards, Kish, L.B., Green, F., Iannaccone, G., and Vig, J.R., Eds., Santa Fe: SPIE, 2003, vol. 5115, p. 40.

12. Smulko, J.M., Kish, L.B., and Schmera, G., Proc. of SPIE Conf. Noise and Information in Nanoelectronics: Sensors and Standards, Kish, L.B., Green, F., Iannaccone, G., and Vig, J.R., Eds., Santa Fe: SPIE, 2003, vol. 5115, p. 92.

13. Yakimov, A.V., Belyakov, A.V., Moryasin, A.V., Perov, M.Yu., and Vandamme, L.K.J., Proc. 17th Conf. on Noise and Fluctuations, Prague, August 18-22, 2003, Sikula, J., Ed., Brno: CNRL, 2003, p.71.

14. Grafov, B.M., Proc. of SPIE Conf. Noise and Information in Nanoelectronics: Sensors and Standards, Kish, L.B., Green, F., Iannaccone, G., and Vig, J.R., Eds., Santa Fe: SPIE, 2003, vol. 5115, p. 16.

15. Grafov, B.M., Elektrokhimiya, 2003, vol. 39, p. 469.

16. Grafov, B.M., Proc. 17th Conf. on Noise and Fluctuations, Prague, August 18-22, 2003, Sikula, J., Ed., Brno: CNRL, 2003, p. 41.

17. Grafov, B.M., Elektrokhimiya, 2003, vol. 39, p. 1116.

18. Wharton, J.A., Corros. Sci., 2003, vol. 45, p. 97.

19. Smulko, J., Darowicki, K., and Zelinski, A., Electrochim. Acta, 2002, vol. 47, p. 1297.

20. Parkhutik, V.P. and Timashev, S.F., Elektrokhimiya, 2000, vol. 36, p. 1378.

21. Suntsov, A.E., Grafov, B.M., and Kuznetsov, A.M., Elektrokhimiya, 1999, vol. 35, p. 892.

22. Sirotinskii, Yu.V., Arutyunov, S.L., Grafov, B.M., and Suntsov, A.E., Elektrokhimiya, 1999, vol. 35, p. 661.
23. Grafov, B.M., Kuznetsov, A.M., and Suntsov, A.E., J. Electroanal. Chem., 1998, vol. 450, p. 55.

24. Grafov, B.M., Elektrokhimiya, 1998, vol. 34, p. 1278.

25. Dawson, J.L., Proc. 1st Int. Symp. Electrochemical Noise Measurement for Corrosion Applications, Kearns, J.R., Scully, J.R., Roberge, P.R., Reichert, D.L., and Dawson, J.L., Eds., Montreal: ASTM, 1996, p. 3.

26. Kolbasov, G.Ya., Elektrokhimiya, 1993, vol. 29, p. 106.

27. Gabrielli, C., Huet, F., and Keddam, M., Electrochim. Acta, 1986, vol. 31, p. 1025.

28. Tyagai, V.A., Elektrokhimiya, 1971, vol. 7, p. 69.

29. Dyke, P.P.G., An Introduction to Laplace Transforms and Fourier Series, Heidelberg: Springer, 2000.

30. Malakhov, A.I., Kumulyantnyi analiz sluchainykh negaussovskikh protsessov $i$ ikh preobrazovanii (A Cumulant Analysis of Random Non-Gaussian Prosesses and Their Transforms), Moscow: Sovetskoe Radio, 1978.

31. Brillinger, D.R., Time Series: Data Analysis and Theory, New York: Holt, Rinehart, and Winston, 1975.

32. Brillinger, D.R., Ann. Math. Stat., 1965, vol. 36, p. 1351.

33. Grafova, I.B. and Grafov, B.M., Elektrokhimiya, 2003, vol. 39, p. 143.

34. Grafov, B.M. and Grafova, I.B., J. Electroanal. Chem., 2001, vol. 502, p. 47.

35. Stratonovich, R.L., Izbrannye voprosy teorii fluktuatsii v radiotekhnike (Some Fluctuation Theory Problems in Radio Engineering), Moscow: Sovetskoe Radio, 1961, part 1.

36. Naidu, P.S., Modern Spectrum Analysis of Time Series, Boca Raton: CRC, 1996, pp. 17, 33, 219.

37. Randles, J.E.B., Disc. Faraday Soc., 1947, vol. 1, p. 11.

38. Ershler, B.V., Disc. Faraday Soc., 1947, vol. 1, p. 269.

39. Tikhonov, V.I. and Tolkachev, A.A., Izv. Akad. Nauk SSSR, Otd. Tekh. Nauk, 1956, no. 12, p. 40. 